\title{
BMJ Open Yoga practice in the UK: a cross- sectional survey of motivation, health benefits and behaviours
}

\author{
Tina Cartwright (D) , ${ }^{1}$ Heather Mason, ${ }^{2}$ Alan Porter, ${ }^{1}$ Karen Pilkington ${ }^{1,3}$
}

To cite: Cartwright $\mathrm{T}$, Mason $\mathrm{H}$, Porter $\mathrm{A}$, et al. Yoga practice in the UK: a cross-sectional survey of motivation, health benefits and behaviours. BMJ Open 2020;10:e031848. doi:10.1136/ bmjopen-2019-031848

\section{- Prepublication history and} additional material for this paper are available online. To view these files, please visit the journal online (http://dx.doi. org/10.1136/bmjopen-2019031848).

Received 30 May 2019 Revised 03 December 2019 Accepted 04 December 2019

A) Check for updates

(c) Author(s) (or their employer(s)) 2020. Re-use permitted under CC BY-NC. No commercial re-use. See rights and permissions. Published by BMJ.

${ }^{1}$ School of Social Sciences, University of Westminster, London, UK

${ }^{2}$ The Minded Institute, Arlington House, London, UK

${ }^{3}$ School of Health and Care

Professions, University of Portsmouth, Portsmouth, UK

Correspondence to Dr Tina Cartwright;

T.Cartwright@westminster.ac.uk

\section{ABSTRACT}

Objectives Despite the popularity of yoga and evidence of its positive effects on physical and mental health, little is known about yoga practice in the UK. This study investigated the characteristics of people who practise yoga, reasons for initiating and maintaining practice, and perceived impact of yoga on health and well-being. Design, setting and participants A cross-sectional online anonymous survey distributed through UK-based yoga organisations, studios and events, through email invites and flyers. 2434 yoga practitioners completed the survey, including 903 yoga teachers: $87 \%$ were women, $91 \%$ white and $71 \%$ degree educated; mean age was 48.7 years.

Main outcome measures Perceived impact of yoga on health conditions, health outcomes and injuries. Relationships between yoga practice and measures of health, lifestyle, stress and well-being.

Results In comparison with national population norms, participants reported significantly higher well-being but also higher anxiety; lower perceived stress, body mass index and incidence of obesity, and higher rates of positive health behaviours. $47 \%$ reported changing their motivations to practise yoga, with general wellness and fitness key to initial uptake, and stress management and spirituality important to current practice. $16 \%$ of participants reported starting yoga to manage a physical or mental health condition. Respondents reported the value of yoga for a wide range of health conditions, most notably for musculoskeletal and mental health conditions. 20.7\% reported at least one yoga-related injury over their lifetime. Controlling for demographic factors, frequency of yoga practice accounted for small but significant variance in health-related regression models $(p<0.001)$.

Conclusion The findings of this first detailed UK survey were consistent with surveys in other Western countries. Yoga was perceived to have a positive impact on physical and mental health conditions and was linked to positive health behaviours. Further investigation of yoga's role in self-care could inform health-related challenges faced by many countries.

\section{INTRODUCTION}

Originating in India as a comprehensive mindbody practice, yoga has become increasing popular in the West as a holistic approach to health and well-being. In the USA, national health surveys indicated a lifetime prevalence

\section{Strengths and limitations of this study}

This is the first comprehensive survey to assess the practice and perceived impact of yoga on health, lifestyle-related behaviours and well-being in the UK.

- The survey design captures the significant number of practitioners who take up yoga to manage a physical or mental health condition, and identifies health conditions for which yoga is rated as most helpful in self-management.

- Despite the large sample, it was self-selected and unlikely to be representative of all yoga practitioners.

- The results relied on retrospective and self-report data which may be subject to memory bias and social desirability.

rate of $13.2 \%$ or 31 million adults in $2012,{ }^{1}$ an increase from $5.1 \%$ a decade earlier. ${ }^{2}$ Surveys also demonstrate significant levels of practice in countries such as Australia ${ }^{3}$ and Germany. ${ }^{4}$ Although there are many different styles of yoga, the main components of yoga include physical postures, breathing techniques, relaxation and meditation. There is growing evidence that yoga is an effective multi-component health intervention that reduces stress, increases physical activity and improves well-being. ${ }^{5-7}$ Clinical studies provide preliminary support for the effectiveness of yoga as an adjunct treatment for a range of chronic conditions such as depression, ${ }^{89}$ anxiety, ${ }^{11}{ }^{11}$ lower back pain ${ }^{12} 13$ and type 2 diabetes. ${ }^{14}{ }^{15}$ Potential physiological mechanisms include down-regulation of the hypothalamic-pituitary-adrenal (HPA) axis and sympathetic nervous system and reduced inflammatory markers. ${ }^{6} 1617$ In addition, psychological mechanisms such as enhanced self and body awareness, coping, mindfulness, self-compassion and social connectedness may underlie healthier lifestyle choices and more adaptive responses to stressors. ${ }^{17}$ Moderate effects have also been reported on cognitive function. ${ }^{18}$ Given the increasing personal and healthcare costs associated with 
lifestyle-related diseases, ${ }^{19} 20$ it is important to better understand the impact of yoga on health-related outcomes in both clinical and naturalistic settings.

Previous surveys, primarily in the USA and Australia, have provided some insight into the characteristics of yoga practitioners, their motivations and yoga's perceived health impact. Yoga practitioners are consistently more likely to be women, white, educated and of higher socioeconomic status. ${ }^{2} 421-23$ This contrasts with a recent survey in India where practitioners were more likely to be men and high school educated, likely to reflect both cultural factors in the perceptions of yoga given its Indian origins and the predominance of children and students in the sample. ${ }^{24}$ While yoga practitioners' health status is higher than population norms, ${ }^{125}$ yoga is used to manage a range of health conditions. For example, in the US National Health Interview Surveys in 2002 and 2012, musculoskeletal and mental health ${ }^{2}$ and back pain, stress and arthritis ${ }^{1}$ were the main health conditions for which people most commonly practised yoga. The majority reported yoga as helpful in managing these conditions. ${ }^{2}$ In Australia, $20 \%$ of those surveyed practised yoga for a specific health reason reported to be improved by yoga, ${ }^{23}$ while $88 \%$ of survey participants in Germany rated their health as improved since starting yoga. ${ }^{4}$ Studies have also found an association between yoga/meditation practice and positive health behaviours such as higher physical activity levels, lower rates of smoking and higher likelihood of vegetarian diet. ${ }^{3232526}$

Several studies have explored motivational factors underlying yoga practice; most commonly cited are general wellness, ${ }^{123}$ health and fitness, ${ }^{23}$ a specific health condition $^{23}$ and improved immune function and energy. ${ }^{1}$ Park et al found that while physical improvement (exercise and flexibility) and stress relief were the most prevalent reasons for adopting yoga, individuals' motives for continuing yoga shifted towards more holistic motivations such as spirituality over time. ${ }^{27}$ Taken together, these surveys indicate that a substantial proportion of the population is attracted to yoga to manage their physical, mental and spiritual health.

It is therefore surprising that little is known about yoga practice in the UK. The Health Survey for England suggested an increasing but relatively low prevalence of yoga practice $(0.46 \%$ in $1997 / 1999,1.11 \%$ in $2006 / 2008) .{ }^{25}$ This was, however, based on responses to the question 'Have you done any other sport or exercise not listed on this card?' and referred to the previous 4 weeks only. The data are now relatively dated and limited in the extent to which they provided insight into decisionmaking around yoga practice. The potential impact of yoga on managing health conditions and increasing health-related behaviours is particularly relevant given the unprecedented increase in long-term conditions and links between comorbidity and poor mental health. ${ }^{20}$ Management of this 'tsunami of need'28 has led to a focus on self-care approaches to reduce lifestyle risk factors and manage chronic conditions. Universal personalised care is included in the recent NHS Long Term Health Plan, ${ }^{29}$ with scope for the inclusion of yoga. ${ }^{30} \mathrm{~A}$ comprehensive survey of current yoga practice in the UK and perceived impact on health conditions, behaviours and well-being is thus timely.

The overall aim of this study was, therefore, to gain a better understanding of current yoga practice in the UK by investigating: (1) the characteristics, lifestyle and wellbeing of those practising yoga in comparison with national norms; (2) yoga practice characteristics; (3) motivations underlying yoga practice; (4) perceived impact of yoga on health outcomes; and (5) the relationship between yoga practice characteristics and well-being.

\section{MATERIALS AND METHODS \\ Design and recruitment}

The study was a cross-sectional survey design using an anonymous online questionnaire hosted on Qualtrics. Recruitment was through UK-based yoga organisations, yoga studios and teachers, marketing at UK yoga events and social media. Information about the study was posted on a dedicated university website and Facebook page and widely advertised by two yoga organisations and at several yoga events (during International Yoga Day, a yoga symposium and an all-party parliamentary group on traditional Indian sciences) with printed flyers and presentations. Email invitations were also sent to 79 studios located in major cities across the UK and identified through online searches, requesting they send the link to their members. Yoga practitioners were invited to participate if they met the inclusion criteria: UK resident, practised yoga within the past 12 months, and were over 18 years. All participants gave informed consent. Data collection took place over a 6-month period (June-December 2016).

\section{Patient and public involvement}

At the pilot stage, 12 yoga practitioners were consulted regarding the aims of the study and content and acceptability of the questionnaire, feedback on which was incorporated into the final survey. Eight were women and five were yoga teachers, aged 33-49 years $(M=41.5 \pm 5.37)$, having practised yoga for $2-20$ years $(M=13.9 \pm 5.2)$.

\section{Survey development}

Previous surveys of yoga practice were reviewed 222326 and a draft set of questions compiled focusing on the key objectives. The final questionnaire was informed by consultations with key yoga researchers and feedback from yoga teachers and practitioners from the pilot.

\section{Socio-demographic variables}

Data was collected on: gender, age, education, ethnicity, marital and employment status, and area of residence. The McArthur scale of subjective social status ${ }^{31}$ is a single item which assesses perceived social ranking on a 10-point ladder with higher scores indicating higher perceived ranking. 


\section{Health, lifestyle and well-being variables}

Health variables included: self-reported height and weight (to calculate body mass index (BMI)), self-rated health (5-point Likert scale), ${ }^{32}$ current health issues (20 listed). Lifestyle variables were assessed with single items and included: smoking status, dietary choices (eg, vegetarian), average weekly alcohol intake (units), average daily fruit/vegetable intake (2 or less, $3-4,5$ or more), weekly frequency of brisk exercise apart from yoga. Warwick-Edinburgh Mental Well-being Scale ${ }^{33}$ assessed subjective well-being and psychological functioning, with higher scores indicating higher well-being. The four single-item Office of National Statistics (ONS) measures of personal well-being assessed: satisfaction with life nowadays, feeling things in life are worthwhile, how happy yesterday, how anxious yesterday, on a 10-point Likert scale (not at all to completely). ${ }^{34}$ The 4 -item Perceived Stress Scale ${ }^{35}$ assessed global life stress, with higher scores indicating higher levels of perceived stress.

\section{Yoga practice characteristics}

This section asked about personal practice of yoga. Fixed-response questions regarding motivation included reason(s) for starting yoga, for maintaining or taking a break from yoga and whether primary motivations had changed over time. Yoga practice questions included duration of yoga practice (years/months), average days per week practising yoga, average weekly hours spent practising both at home and in class. Fixed-response questions asked about preferred style of yoga, class location and percentage of time spent on different components (physical poses, breathwork, relaxation, meditation, others). Additional questions asked about use of yoga therapy in past 12 months, any independent meditation practice, including hours spent meditating, and amount spent on yoga classes/workshops per month. Participants were asked whether they were yoga teachers or therapists.

\section{Perceived health impact}

Participants were asked to indicate if they had experienced specific health conditions/issues since practising yoga ( 25 conditions listed with the option to specify other issues) and rate perceived helpfulness of yoga in managing the condition on a 5-point Likert scale (from very helpful to very unhelpful). Participants were also asked to rate on a 5-point Likert scale (from strongly disagree to strongly agree) the extent to which they perceived yoga impacted on seven domains of health (physical, mental, stress, strength, flexibility, sleep and lifestyle) identified by previous surveys. ${ }^{26}$

\section{Yoga-related injuries}

Fixed-response questions relating to up to three injuries sustained as a result of yoga practice including: body location, new or recurring injury, circumstances around occurrence (eg, unsupervised or while receiving an adjustment) and yoga style practised when injury occurred (open response). Respondents were not asked about the severity or duration of any injuries.

\section{Data analysis}

Data were cleaned to identify miscoded and missing data. Missing cases were deleted listwise. Descriptive statistics were calculated for socio-demographic characteristics, yoga practice variables, health and lifestyle variables. Percentages were calculated according to total responses to item (valid percent). Gender and other group differences were analysed using t-tests and $\chi^{2}$ tests. Comparisons with UK normative data, where available, were analysed using 1-sample t-tests and $\chi^{2}$ tests. Pearson's and Spearman's correlations were computed to assess relationships between yoga practice variables and yoga impact and health-related variables, respectively, and determine predictor variables for the regression analyses. Hierarchical multiple regression analyses were used to examine the independent effect of demographics, yoga variables, yoga teacher status and meditation practice on health outcomes including stress, well-being, satisfaction with life, worthwhile life, happiness and anxiety as criterion variables.

\section{RESULTS}

2635 people responded to the survey, with 2434 people meeting the inclusion criteria and completing at least the first question about yoga participation.

\section{Socio-demographic characteristics}

Sociodemographic characteristics are presented in table 1; the majority of respondents were women, white, well educated $(71 \% \geq$ degree), with a wide age range (18-92 years, $M=48.7 \pm 12.5$ ). Participants rated themselves as above average in terms of subjective social status $(\mathrm{M}=6.62 \pm 1.47)$. All areas of the UK were represented although London and the south of England were most prevalent. Forty percent of the sample were yoga teachers $(n=903)$.

\section{Lifestyle and health characteristics and comparison with UK norms}

Participants reported a range of current health conditions, most frequently: stress $(n=340)$, sleep issues $(\mathrm{n}=261)$, anxiety $(\mathrm{n}=254)$, arthritis $(\mathrm{n}=201)$, menopausal symptoms $(n=213)$, musculoskeletal problems $(n=178)$, irritable bowel syndrome $(n=123)$ and asthma $(n=119)$. Very few participants reported heart disease $(n=9)$, chronic obstructive pulmonary disease $(n=6)$, epilepsy $(n=10)$ or diabetes $(n=18)$.

Given that teachers are likely to differ from non-teachers in health characteristics and yoga practice, ${ }^{23}$ table 2 shows descriptive data for each group separately and combined to enable comparisons with national norms, where available. Both groups compared favourably with health and lifestyle norms. Only $4.2 \%$ currently smoked, significantly lower than $15.1 \%$ in the general adult UK population. ${ }^{36}$ 
Table 1 Socio-demographic characteristics of sample

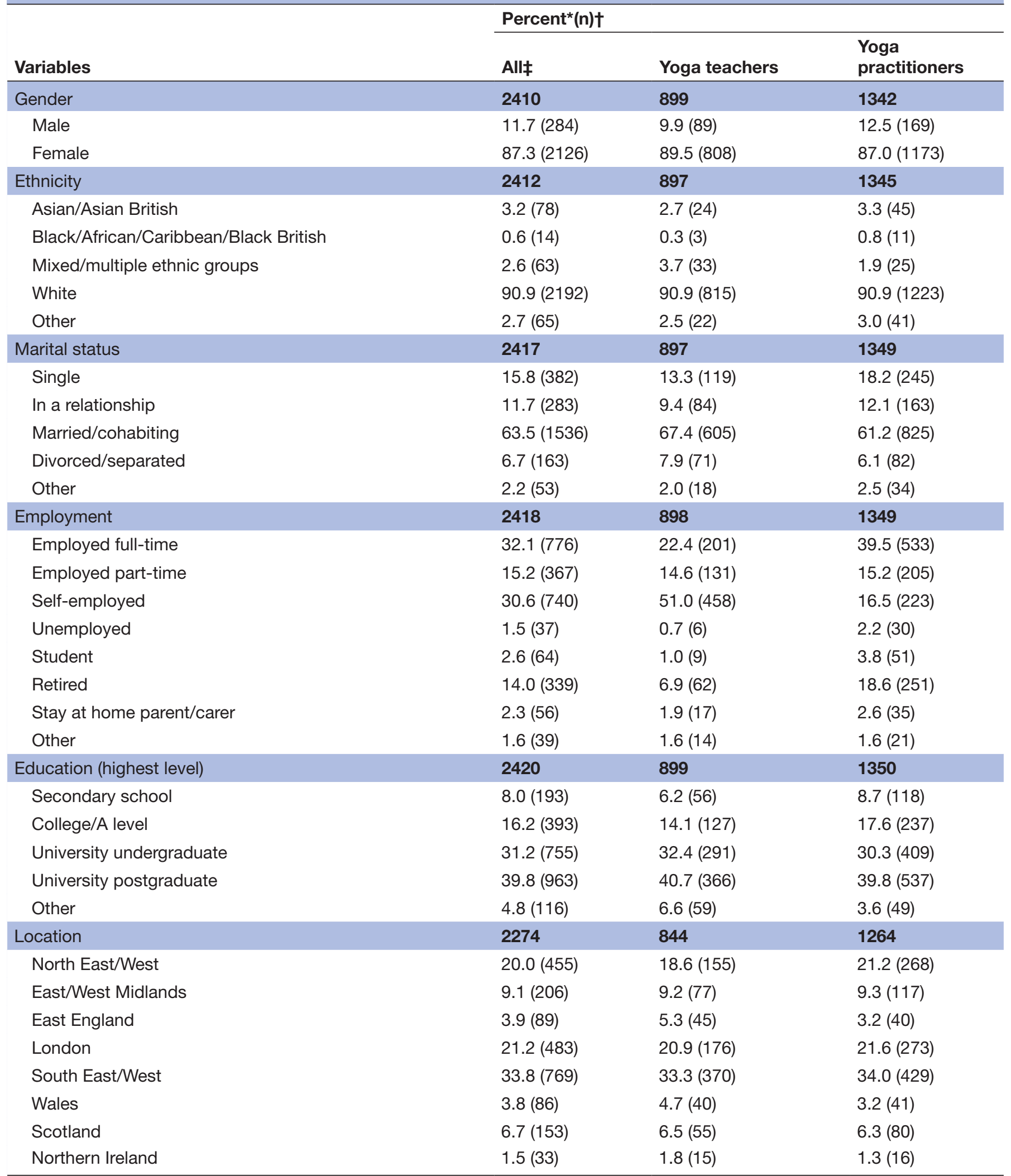

*Of total responses (valid percent).

$\dagger \mathrm{N}$ for each variable in bold type.

†Includes participants who did not state whether yoga teacher or not. 
Table 2 Health, lifestyle and yoga practice variables of complete sample, yoga teachers and yoga practitioners

\section{Percent* (n)}

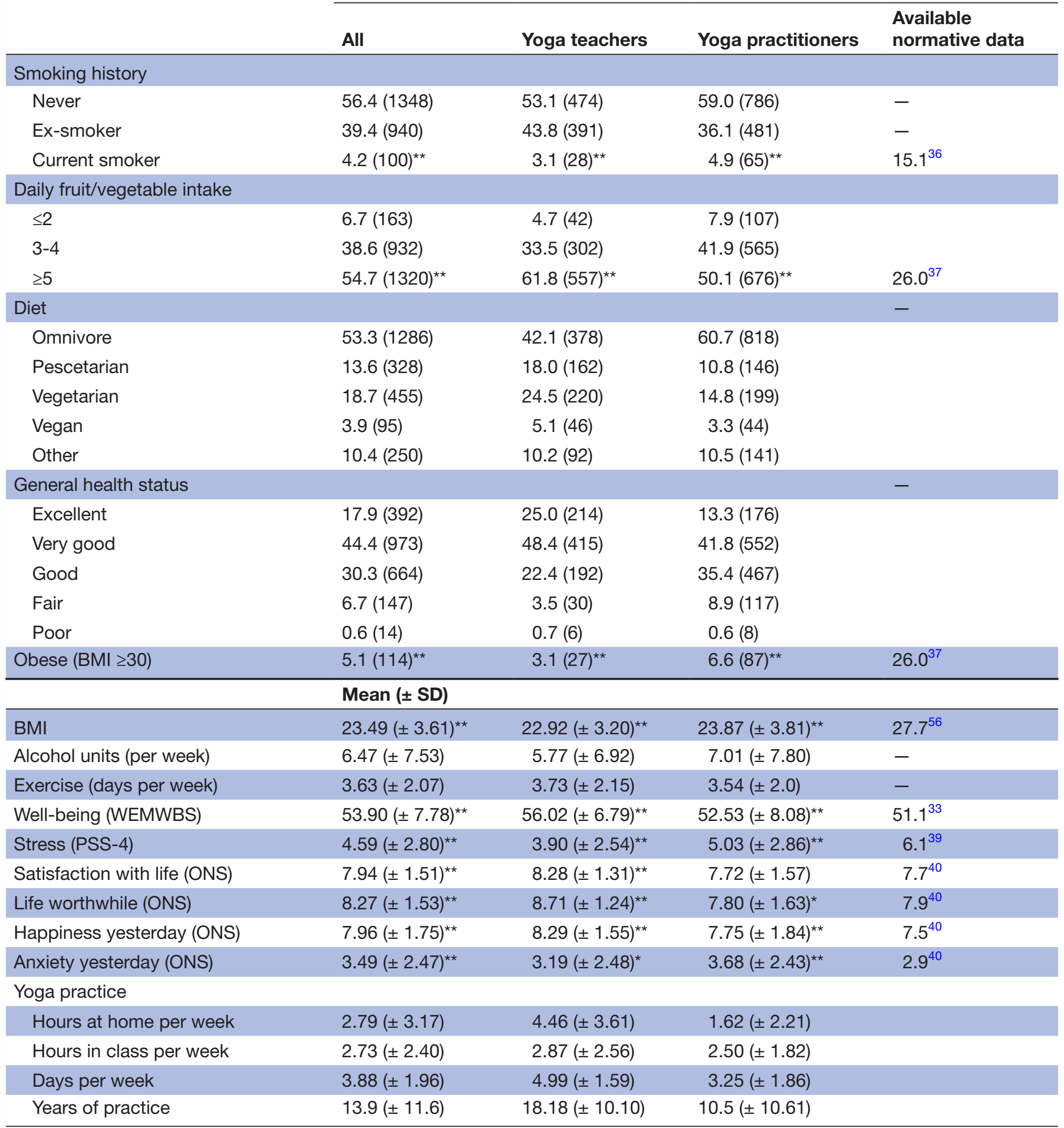

${ }^{*} \mathrm{P}<0.05 ;{ }^{* *} \mathrm{p}<0.0005$ (see table 1 in online supplementary material for further details).

†Of total responses (valid percent). Significantly different from available norms using $\chi^{2}$ and 1-sample t-tests.

BMI, body mass index; ONS, Office of National Statistics; PSS, Perceived Stress Scale; WEMWBS, Warwick-Edinburgh Mental Well-being Scale.

Similarly, $55 \%$ reported the recommended intake of daily fruit/vegetable servings, significantly higher than $26 \%$ in the population. ${ }^{37}$ In addition, $22.6 \%$ were vegetarian/vegan and $13.6 \%$ pescetarian. Average BMI was
23 (normal), with only $5.1 \%$ of the sample obese, both significantly lower than national figures. ${ }^{37}$ The majority $(93.5 \%)$ reported engaging in brisk exercise on at least 1 day per week $(M=3.6)$. Self-reported alcohol intake was 


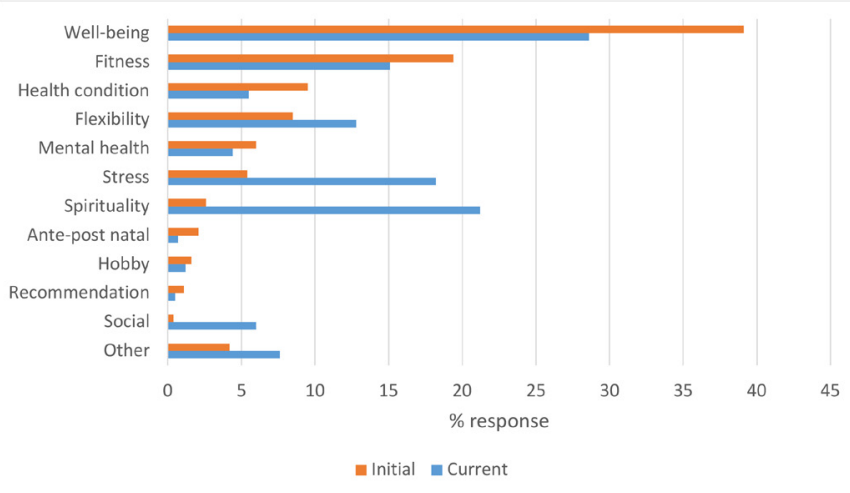

Figure 1 Initial and current principal reasons for practising yoga.

substantially below the recommended maximum weekly intake of 14 units. ${ }^{38}$

The majority rated their general health as good, very good or excellent $(92.6 \%)$. Well-being was significantly higher $^{33}$ and perceived stress lower ${ }^{39}$ than norms in England for all participants. For yoga teachers, ONS wellbeing items compared favourably with norms for life satisfaction, life worthwhile and happiness. For non-teachers, happiness was higher, but feeling life worthwhile was lower than norms. In addition, feeling anxious was higher than population norms for all participants. ${ }^{40}$

Men did not differ significantly from women on smoking, fruit/vegetable intake or exercise, but had higher BMI $(\mathrm{M}=24.3$ and 23.4; $\mathrm{t}=4.16, \mathrm{df}=2330, \mathrm{p}<0.0025)$ and alcohol intake $(\mathrm{M}=8.7$ and $6.2 ; \mathrm{t}=3.29, \mathrm{df}=2021$, $\mathrm{p}<0.001)$. For health and well-being measures, women differed only on feeling life was more worthwhile $(\mathrm{M}=8.3$ and $8.1 ; \mathrm{t}=2.36, \mathrm{df}=2171, \mathrm{p}<0.05)$.

\section{Yoga practice characteristics}

Yoga practice frequency is summarised in table 2, indicating high levels of yoga practice in both teachers and non-teachers. Participants reported practising yoga from less than 1 to 56 years, with teachers having practised for longer and more frequently at home and in class $(\mathrm{p}<0.0005)$. Men reported practising for a shorter duration than women $(\mathrm{M}=11.7$ and $14.18 ; \mathrm{t}=3.23, \mathrm{df}=2355$, $\mathrm{p}<0.001$ ), but did not differ on other characteristics. Diverse styles of yoga were reported, with Hatha (28\%), Iyengar (25.3\%), Vinyasa flow (14.8\%) and Ashtanga $(7.2 \%)$ most frequently reported. The most popular venues were: yoga studio $(57.5 \%)$, community hall $(38 \%)$ and gym $(25.1 \%)$, with $20.7 \%$ practising at home using online resources or DVDs. Participants spent an average of $£ 50.13( \pm 61.55)$ on classes/workshops per month. $64.6 \%$ of practice time was spent on physical postures, $13.1 \%$ breathwork, $12.0 \%$ relaxation, $8.6 \%$ meditation and $1.9 \%$ other practices such as chanting and study. $15.8 \%$ reported attending one-to-one yoga sessions and $12.8 \%$ yoga therapy sessions in the past 12 months. Over half $(51.5 \%)$ of participants reported undertaking meditation practice independent of their yoga practice.

\section{Motivations}

A comparison of initial and current motivations for practice is shown in figure 1. Principal initial reasons were for general wellness (39\%), fitness (19\%) and flexibility (8.5\%). $16 \%$ of participants reported starting yoga for a physical $(9.5 \%)$ or mental health condition $(6 \%)$, with musculoskeletal conditions and anxiety/depression most commonly cited. Almost half (47\%) of participants reported a change in focus over time, most notably in relation to spirituality (21\%), stress management (18\%) and social interaction $(6 \%)$.

\section{Perceived health impact}

Participants' rated the extent to which they felt yoga had improved seven aspects of health incorporating physical, mental and lifestyle dimensions. The majority either agreed or strongly agreed that yoga had improved their physical health $(88 \%)$, mental health $(86.2 \%)$, stress levels $(82.6 \%)$, strength $(87.1 \%)$ and flexibility $(91.6 \%)$. In addition, $69.3 \%$ reported lifestyle changes perceived as resulting from their yoga practice and $57.4 \%$ sleep improvement.

All yoga practice variables were significantly correlated with perceived health impact (see table 2 in online supplementary material), with greater yoga frequency and duration associated with higher perceived impact. However, frequency of practise, both in terms of hours at home per week and days per week, was most strongly correlated with all health impact variables, with the strongest relationship for home practice and lifestyle changes $\left(r_{s}=0.411, n=1902, p<0.0005\right)$.

Participants rated perceived helpfulness for a range of health conditions/issues they had experienced before or since practising yoga (table 3 ). In particular, a history of musculoskeletal and mental health issues were reported by a large number of our participants, with the majority reporting yoga as helpful or very helpful in managing these conditions.

\section{Yoga-related injuries}

When asked about injuries attributable to yoga practice, $67.6 \%(\mathrm{n}=1646)$ reported no injuries, $20.7 \%(\mathrm{n}=504)$ at least one injury, $5.4 \%(\mathrm{n}=131)$ a second, and $1 \%(\mathrm{n}=24)$ a third injury. Back $(24.0 \%)$, knee $(13.1 \%)$, shoulder $(12.5 \%)$, neck $(7.5 \%)$, wrist $(6.0 \%)$ and foot/ankle (3.4\%) injuries were most common. The majority $(72 \%)$ were new injuries and occurred in class across (48.6\%), from following a specific instruction $(13.5 \%)$ or receiving an adjustment from a teacher $(11.2 \%)$, with a further $26.6 \%$ during unsupervised/home practice. A range of yoga styles and specific postures were listed in association with individual injuries.

Relationship between yoga practice characteristics and stress and well-being

Hierarchical regression models with age and gender entered in the first step and yoga practice variables, teacher status and meditation practice in subsequent 
Table 3 Perceived helpfulness in managing health issues and conditions

\begin{tabular}{|c|c|c|c|c|}
\hline Condition & $\mathrm{n}^{*}$ & $\begin{array}{l}\text { Helpful } \\
\text { (\%) }\end{array}$ & $\begin{array}{l}\text { Neither } \\
\text { helpful nor } \\
\text { unhelpful }\end{array}$ & $\begin{array}{l}\text { Unhelpful } \\
(\%)\end{array}$ \\
\hline \multicolumn{5}{|l|}{ Musculoskeletal } \\
\hline Back pain & 1070 & 94.8 & 3.8 & 1.4 \\
\hline Neck/shoulder pain & 903 & 91.7 & 6.2 & 2.1 \\
\hline Arthritis & 261 & 87 & 12.3 & 0.8 \\
\hline Other & 424 & 82.8 & 2.4 & \\
\hline \multicolumn{5}{|l|}{ Mental health } \\
\hline Stress & 997 & 98.4 & 1.4 & 0.2 \\
\hline Anxiety & 712 & 96.8 & 2.9 & 0.2 \\
\hline Depression & 513 & 93.2 & 5.5 & 1.4 \\
\hline Sleep issues & 463 & 79 & 19.7 & 1.2 \\
\hline Other & 75 & 96 & 4 & 0 \\
\hline \multicolumn{5}{|l|}{ Women's health } \\
\hline Pre/post pregnancy & 86 & 89.5 & 8.1 & 2.3 \\
\hline $\begin{array}{l}\text { Pre-menstrual } \\
\text { syndrome }\end{array}$ & 275 & 76.5 & 22.5 & 0.7 \\
\hline $\begin{array}{l}\text { Menopause } \\
\text { (symptoms) }\end{array}$ & 224 & 68.7 & 29.4 & 1.9 \\
\hline Other & 98 & 77.6 & 21.4 & 1 \\
\hline \multicolumn{5}{|l|}{ Cardiovascular } \\
\hline High blood pressure & 160 & 73 & 26.3 & 0.6 \\
\hline Other & 57 & 66.7 & 31.6 & 1.8 \\
\hline \multicolumn{5}{|l|}{ Respiratory } \\
\hline Asthma & 214 & 72.4 & 27.1 & 0.5 \\
\hline Other & & & & \\
\hline
\end{tabular}

\begin{tabular}{lllll}
$\begin{array}{l}\text { Gastrointestinal } \\
\begin{array}{l}\text { Irritable bowel } \\
\text { syndrome }\end{array}\end{array}$ & 309 & 69.3 & 29.8 & 1 \\
$\begin{array}{l}\text { Other } \\
\text { Neurological }\end{array}$ & 98 & 68.4 & 26.5 & 5.1 \\
\hline Migraines & 243 & 54.7 & 41.2 & 4.1 \\
Headaches & 415 & 68.7 & 22.3 & 2.7 \\
Other & 53 & 83 & 17 & 0 \\
\hline Other & & & & \\
Allergies & 296 & 27.2 & 66.4 & 6.4 \\
Fertility issues & 74 & 32.4 & 58.1 & 9.5 \\
\hline
\end{tabular}

*Number stating they had experienced the health condition/issue before or since practising yoga. Only conditions with responses greater than $50(n)$ are included.

steps were all significant in predicting stress and wellbeing criterion variables (table 4). Age was positively associated with all well-being variables and negatively with stress and anxiety. Frequency of yoga practice, but not duration of yoga practice, contributed additional variance in all models except anxiety. Number of days practised per week was a predictor for measures of stress and well-being, while frequency of home and/or class practice (hours) were independent predictors of life satisfaction, feeling life was worthwhile and happiness. Teacher status and having an independent meditation practice were significant predictors but accounted for very small additional variance. Frequency of yoga, teacher status and meditation practice were positively associated with wellbeing variables and negatively with stress.

\section{DISCUSSION}

This is the first comprehensive survey of yoga practice in the UK. Demographic findings were broadly consistent with those in other Western countries, with practitioners' predominately women, white and well educated. Compared with UK population norms, participants reported higher well-being and positive health behaviours and lower stress, BMI and obesity. While this cannot be linked specifically to yoga given the cross-sectional nature of the study, the vast majority of participants reported that yoga had improved their physical and mental health, with two thirds attributing lifestyle changes to their yoga practice. This was associated with frequency of yoga practice rather than overall length of practising. Importantly, our survey found that participants perceived yoga as helpful in managing a wide range of health conditions, most notably musculoskeletal conditions and mental health, consistent with findings in the $\mathrm{USA}^{2}$ and clinical trials. ${ }^{11} 13$ This suggests that yoga is used in the UK to manage health conditions and support well-being and has further potential to support self-care of debilitating and costly health disorders.

As expected, lifestyle variables compared favourably with the general UK population. These findings are consistent with studies in other developed countries. ${ }^{325}{ }^{26}$ Similarly, well-being was higher ${ }^{33} 40$ and stress lower ${ }^{39}$ than national norms, particularly for teachers which may reflect their stronger commitment and immersion in yoga ${ }^{4}$ or could reflect reporting bias. Anxiety, however, was higher than population norms ${ }^{40}$ for all participants and was also the most commonly cited current health issue. This reflects the complex relationship between yoga and physical and mental health, as noted in previous research. ${ }^{21}$ It may be a manifestation of a number of factors such as higher awareness of emotional distress associated with improved interoception resulting from yoga practice, ${ }^{41}$ greater willingness to report mental distress and higher engagement in mindful and holistic practices in this particular population. ${ }^{42}$ Yoga practitioners report better than average overall health, ${ }^{46} 43$ but commonly report mental health issues, ${ }^{22}$ frequently seeking out yoga to manage mental health conditions such as anxiety and depression. Indeed, over $90 \%$ of our sample found yoga helpful for such conditions.

Consistent reports of healthier lifestyles, lower levels of stress and higher levels of well-being in yoga practitioners compared with population figures are important given the increases in disease arising from modifiable health behaviours $^{20}$ and in mental illness. ${ }^{44}$ Although this may partly reflect our white, educated, female sample, there 


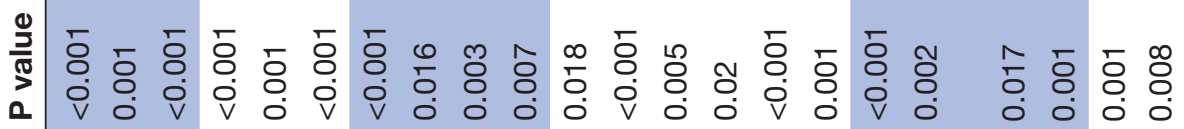

莳市

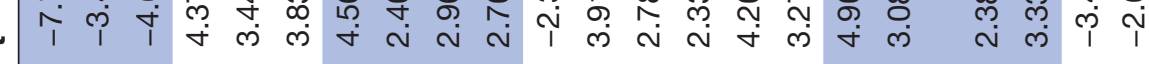

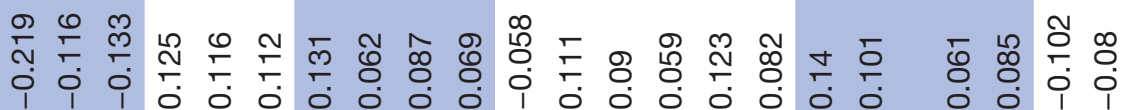

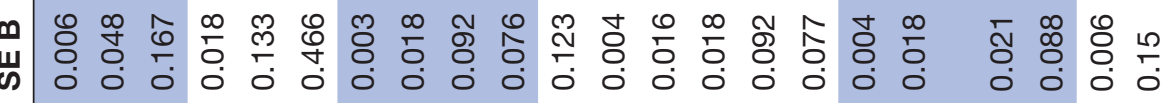

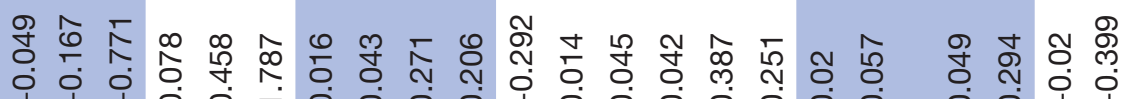

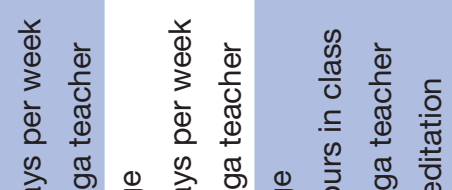

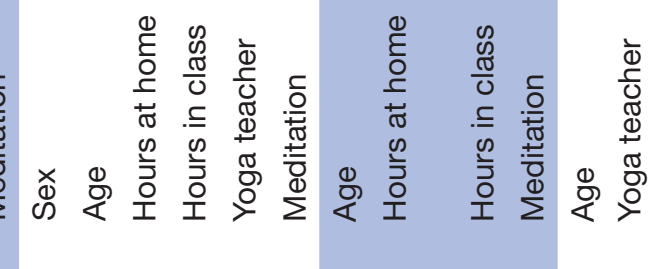

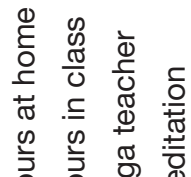

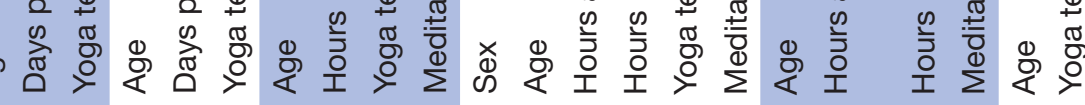

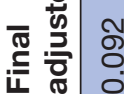
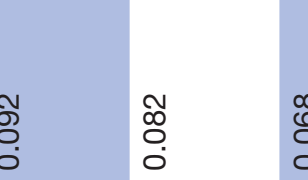

\begin{tabular}{l}
$*$ \\
\multirow{2}{*}{${ }^{*}$} \\
$\stackrel{0}{0}$ \\
0
\end{tabular}

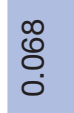

ริ
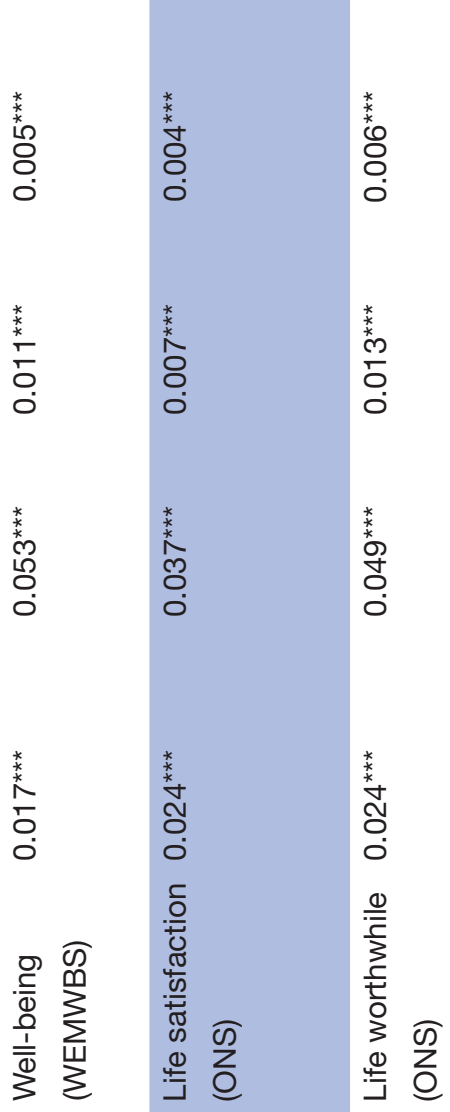

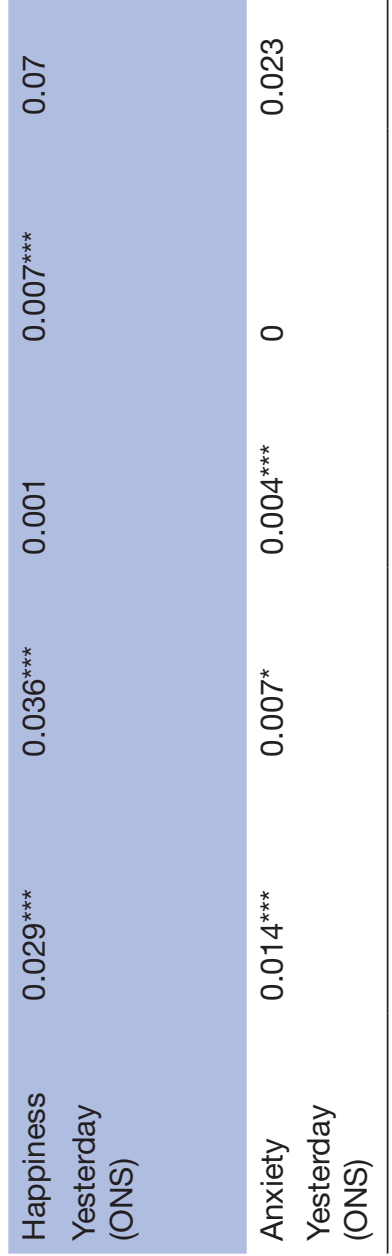

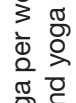

징 항

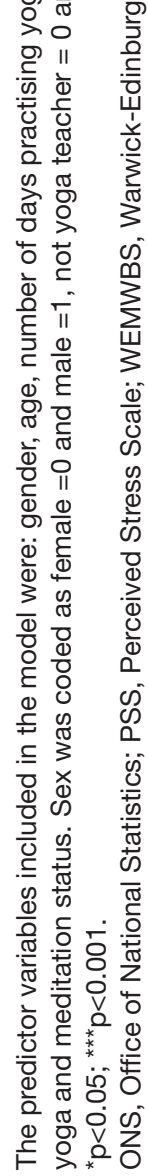


were few gender differences in health and behavioural outcomes. Other possible explanations include attitudinal change in line with ethical guidelines on lifestyle, ${ }^{3}$ reinforcement of positive affect associated with positive health behaviours ${ }^{45}$ and greater body awareness increasing motivation to take up other healthy behaviours. ${ }^{46}$ Isolating the specific causal effects of yoga practice on behavioural outcomes is challenging but warrants further testing in controlled studies with long-term follow-up. In addition, understanding the factors underlying gender differences in yoga practice is important given the higher rates of lifestyle-related morbidity in men and challenges around engaging men in health protective behaviours. ${ }^{47}$ Further exploration of the gender differential is warranted and could draw on the perceptions of yoga in Western countries compared with those in India.

Few studies have explored changes in motivation over time and yet almost half of our participants stated that their focus had changed, particularly towards a more holistic psycho-spiritual approach, which mirrors the findings of Park $e t a l$ s smaller study. ${ }^{27}$ This may also reflect a growth in commitment to yoga as a holistic lifestyle practice and underlie behavioural shifts towards a healthier lifestyle. A more spiritual focus has also been found to be associated with higher psychological well-being. ${ }^{48}$ Yoga experience varied considerably but frequency of practice was a stronger predictor of health outcomes than years of practice, consistent with previous findings. ${ }^{22}$ Additional meditation practice was linked to higher positive well-being but not perceived stress or anxiety, perhaps surprising given the evidence for meditation as a stress reduction tool. ${ }^{49}$

Yoga-practice variables accounted for a relatively small amount of variance in health and well-being measures as has been found in previous studies. ${ }^{42}$ Nevertheless, this variance is significant and since yoga is an accessible form of practice for all ages and levels of fitness, it provides an important benefit to psychological health. ${ }^{22}$ The high levels of yoga practice in our sample and significance of yoga frequency as a predictor variable suggest the importance of a regular yoga practice for health benefit. Higher yoga involvement has been associated with higher mindfulness, spiritual well-being and lower psychiatric symptoms. ${ }^{50}$ The 'hedonic treadmill' describes the difficulty of creating lasting change to our levels of well-being and happiness due to habituation to our circumstances, thereby diminishing the impact of life events that increase short-term happiness such as a lottery win. ${ }^{51}$ In contrast, activities, such as yoga, that offer small but frequent boosts to well-being may provide an effective mechanism to increase longer-term well-being due to their cumulative effects. ${ }^{52}$

Consistent with previous studies, respondents strongly believed that yoga had a positive impact on their physical and mental health. ${ }^{232}$ Many reported its value in managing a range of health conditions, most notably musculoskeletal and mental health conditions. This augments clinical research on the effectiveness of yoga by demonstrating that people are perceiving health benefit in naturalistic settings. However, few respondents reported cardiovascular disease and diabetes, consistent with a previous nationally representative UK survey, ${ }^{25}$ despite the potential benefits of yoga as an ancillary and preventative treatment. ${ }^{1553}$ This may reflect a lack of perceived relevance or feasibility of practising yoga for people with these conditions or simply reflect the demographics of our sample. Nevertheless, future research should investigate the attitudes towards yoga of people with these conditions to more fully understand their under-representation.

Like any physical activity, yoga is not without the potential for adverse effects. Yoga-related injuries were consistent with a recent systematic review of nine observational studies, which found a lifetime prevalence of $35.4 \% .^{54}$ While we did not assess severity, Cramer et al reported that adverse effects were predominately relatively minor, musculoskeletal injuries consistent with our findings. In our study, a range of yoga styles were associated with injuries reflecting the diversity of styles practised by respondents, Cramer suggesting that frequency or intensity of practice may be a stronger predictor of injury than yoga style. Taken together, yoga does not appear to pose a greater risk than other physical activities, ${ }^{54}$ but further investigation of precise risk factors would be of value.

\section{Limitations}

This is the first large cross-sectional study in the UK to investigate yoga practice and its impact on health. Nevertheless, the sample was self-selected with a high proportion of yoga teachers so is unlikely to be representative and may be biased towards more positive evaluations of yoga. The results relied on retrospective and self-report data which may be subject to memory bias and social desirability, particularly with regard to self-reporting of weight. ${ }^{55}$ In addition, the cross-sectional design precludes causal inferences about the relationship between yoga practice and health outcomes. The findings are, however, remarkably consistent with surveys in other Western countries, including representative national health surveys, suggesting the findings are relatively robust.

\section{CONCLUSION}

Compared with population norms, yoga practitioners reported higher health, well-being and rates of health protective behaviours, and lower health risk behaviours, stress, BMI and obesity. Yoga practitioners reported a range of reasons for initiating and maintaining yoga practice with their focus changing from physical to psychospiritual factors over time, a potential factor underlying behavioural maintenance and integration of a healthy lifestyle. Yoga was perceived as helpful for managing a variety of physical and psychological health issues suggesting that yoga is commonly used to support self-care and manage health conditions. It is, thus, pertinent to consider in what ways this holistic approach to health and well-being could help address the complex health-related issues with which many countries are now grappling. The results also suggest further investigation is required into the reasons 
for gender differences in prevalence of yoga practice, the specific risk factors for reported adverse events and factors underlying changes in motivation to practice.

Acknowledgements The authors would like to thank Eleanor Connolly for her assistance with questionnaire development and data collection, and Professor Sat Bir Khalsa, Professor Holger Cramer and Dr Anna Cheshire for their feedback on the initial questionnaire. They would also like to express their gratitude to all yoga studios, teachers and the British Wheel of Yoga for promoting the survey and to participants for taking their time to complete the questionnaire.

Contributors KP, TC and HM conceived and designed the study. TC and KP managed recruitment and TC and AP conducted data analysis. TC and KP wrote the paper with contributions from all authors. All authors read and approved the final manuscript.

Funding The authors have not declared a specific grant for this research from any funding agency in the public, commercial or not-for-profit sectors.

Competing interests $\mathrm{HM}$ creates treatment and training programmes for professionals to use yoga and mindfulness techniques with long-term health conditions. Individuals and organisations (including health services) pay for attendance of trainings and courses.

\section{Patient consent for publication Not required.}

Ethics approval The study was approved by the University of Westminster Ethics Committee (1516-0614). Participants gave informed consent before taking part in the study.

Provenance and peer review Not commissioned; externally peer reviewed.

Data availability statement № data are available.

Open access This is an open access article distributed in accordance with the Creative Commons Attribution Non Commercial (CC BY-NC 4.0) license, which permits others to distribute, remix, adapt, build upon this work non-commercially, and license their derivative works on different terms, provided the original work is properly cited, appropriate credit is given, any changes made indicated, and the use is non-commercial. See: http://creativecommons.org/licenses/by-nc/4.0/.

\section{ORCID iD}

Tina Cartwright http://orcid.org/0000-0003-3416-468X

\section{REFERENCES}

1 Cramer H, Ward L, Steel A, et al. Prevalence, patterns, and predictors of yoga use: results of a U.S. nationally representative survey. Am J Prev Med 2016;50:230-5.

2 Birdee GS, Legedza AT, Saper RB, et al. Characteristics of yoga users: results of a national survey. J Gen Intern Med 2008;23:1653-8.

3 Cramer $\mathrm{H}$, Sibbritt $\mathrm{D}$, Park CL, et al. Is the practice of yoga or meditation associated with a healthy lifestyle? results of a national cross-sectional survey of 28,695 Australian women. J Psychosom Res 2017;101:104-9

4 Cramer H, Quinker D, Pilkington K, et al. Associations of yoga practice, health status, and health behavior among yoga practitioners in Germany-Results of a national cross-sectional survey. Complement Ther Med 2019;42:19-26

5 Khalsa SB, Cohen L, McCall T, et al. Principles and Practice of Yoga in Health Care. Edinburgh: Handspring, 2016.

6 Pascoe MC, Bauer IE. A systematic review of randomised control trials on the effects of yoga on stress measures and mood. $J$ Psychiatr Res 2015;68:270-82

7 Büssing A, Michalsen A, Khalsa SBS, et al. Effects of yoga on mental and physical health: a short summary of reviews. Evid Based Complement Alternat Med 2012;2012:1-7.

8 Cramer $\mathrm{H}$, Lauche R, Langhorst J, et al. Yoga for depression: a systematic review and meta-analysis. Depress Anxiety 2013;30:1068-83.

9 Pilkington K, Kirkwood G, Rampes $\mathrm{H}$, et al. Yoga for depression: the research evidence. J Affect Disord 2005;89:13-24

10 Kirkwood G, Rampes H, Tuffrey V, et al. Yoga for anxiety: a systematic review of the research evidence. Br J Sports Med 2005;39:884-91.

11 Cramer H, Lauche R, Anheyer D, et al. Yoga for anxiety: a systematic review and meta-analysis of randomized controlled trials. Depress Anxiety 2018;35:830-43.
12 Cramer $\mathrm{H}$, Lauche $\mathrm{R}$, Haller $\mathrm{H}$, et al. A systematic review and metaanalysis of yoga for low back pain. Clin J Pain 2013;29:450-60.

13 Wieland LS, Skoetz N, Pilkington K, et al. Yoga treatment for chronic non-specific low back pain. Cochrane Database Syst Rev 2017;16.

14 Cramer H, Langhorst J, Dobos G, et al. Yoga for metabolic syndrome: a systematic review and meta-analysis. Eur J Prev Cardiol 2016;23:1982-93.

15 Thind $\mathrm{H}$, Lantini R, Balletto BL, et al. The effects of yoga among adults with type 2 diabetes: a systematic review and meta-analysis. Prev Med 2017;105:116-26

16 Pascoe MC, Thompson DR, Ski CF. Yoga, mindfulness-based stress reduction and stress-related physiological measures: a metaanalysis. Psychoneuroendocrinology 2017;86:152-68.

17 Riley KE, Park CL. How does yoga reduce stress? A systematic review of mechanisms of change and guide to future inquiry. Health Psychol Rev 2015;9:379-96.

18 Gothe NP, McAuley E, Yoga ME. Yoga and cognition: a meta-analysis of chronic and acute effects. Psychosom Med 2015;77:784-97.

19 Scarborough P, Bhatnagar P, Wickramasinghe KK, et al. The economic burden of ill health due to diet, physical inactivity, smoking, alcohol and obesity in the UK: an update to 2006-07 NHS costs. J Public Health 2011;33:527-35.

20 Kingston A, Robinson L, Booth $\mathrm{H}$, et al. Projections of multimorbidity in the older population in England to 2035: estimates from the population ageing and care simulation (PACSim) model. Age Ageing 2018;47:374-80.

21 Park CL, Braun T, Siegel T. Who practices yoga? A systematic review of demographic, health-related, and psychosocial factors associated with yoga practice. J Behav Med 2015;38:460-71.

22 Ross A, Friedmann E, Bevans M, et al. Frequency of yoga practice predicts health: results of a national survey of yoga practitioners. Evid Based Complementary Altern Med 2012;2012:1-10.

23 Penman S, Stevens P, Cohen M, et al. Yoga in Australia: results of a national survey. Int J Yoga 2012;5:92-101.

24 Telles S, Sharma SK, Singh N, et al. Characteristics of yoga practitioners, motivators, and yoga techniques of choice: a crosssectional study. Frontiers in Public Health 2017;5.

25 Ding D, Stamatakis E. Yoga practice in England 1997-2008: prevalence, temporal trends, and correlates of participation. BMC Res Notes 2014;7:172.

26 Ross A, Friedmann E, Bevans M, et al. National survey of yoga practitioners: mental and physical health benefits. Complement Ther Med 2013;21:313-23

27 Park CL, Riley KE, Bedesin E, et al. Why practice yoga? Practitioners' motivations for adopting and maintaining yoga practice. J Health Psychol 2016;21:887-96.

28 Dillner L. How services for long term conditions could be reborn. BMJ 2011;342:1730.

29 The NHS long term plan 2019, 2019. Available: https://www. longtermplan.nhs.uk/ [Accessed 1 Mar 2019].

30 Selbie D. Health and what we mean by that. yoga in healthcare conference. University of Westminster, 2019.

31 Operario D, Adler NE, Williams DR. Subjective social status: reliability and predictive utility for global health. Psychol Health 2004;19:237-46.

32 Lundberg O, Manderbacka K. Assessing reliability of a measure of self-rated health. Scand J Soc Med 1996;24:218-24.

33 Stewart-Brown S, Janmohamed K. Warwick-Edinburgh mental wellbeing scale (WEMWBS) user guide, version 1, 2008. Available: http:// www.healthscotland.com/documents/2702.aspx

34 Office for national statistics (ONS). wellbeing survey user guide. Available: https://www.ons.gov.uk/peoplepopulationandcommunity/ wellbeing/methodologies/personalwellbeingsurveyuserguide2016 [Accessed Feb 2016].

35 Cohen S, Kamarck T. Mermelstein R. a global measure of perceived stress. Journal of Health and Social Behavior 1983;24:385-96.

36 Office for national statistics (ONS). adult smoking habits in the UK: 2017, 2018. Available: https://www.ons.gov.uk/peoplepopulation andcommunity/healthandsocialcare/healthandlifeexpectancies/ bulletins/adultsmokinghabitsingreatbritain/2017 [Accessed 1 March 2019].

37 Office for National Statistics (ONS). Statistics on Obesity, Physical Activity and Diet - England, 2018, 2018. Available: https://digital. nhs.uk/data-and-information/publications/statistical/statistics-onobesity-physical-activity-and-diet/statistics-on-obesity-physicalactivity-and-diet-england-2018 [Accessed 1 Mar 2019].

38 Department of Health. Alcohol guidelines Review-Report from the guidelines development group to the UK chief medical officers 2016.

39 Warttig SL, Forshaw MJ, South J, et al. New, normative, Englishsample data for the short form perceived stress scale (PSS-4). $J$ Health Psychol 2013;18:1617-28. 
40 Office for National Statistics (ONS). Personal well-being in the UK: October 2016 to September 2017. Available: https://www.ons.gov. uk/peoplepopulationandcommunity/wellbeing/bulletins/measuringnat ionalwellbeing/october2016toseptember2017, 2018 [Accessed 28 Jan 2019].

41 Farb N, Daubenmier J, Price CJ, et al. Interoception, contemplative practice, and health. Front Psychol 2015;6.

42 Bystritsky A, Hovav S, Sherbourne C, et al. Use of complementary and alternative medicine in a large sample of anxiety patients. Psychosomatics 2012;53:266-72.

43 Sibbritt D, Adams J, van der Riet P. The prevalence and characteristics of young and mid-age women who use yoga and meditation: results of a nationally representative survey of 19,209 Australian women. Complement Ther Med 2011;19:71-7

44 Department of Health. No health without mental health: a cross government mental health outcomes strategy for people of all ages, 2011. Available: https://assets.publishing.service.gov.uk/ government/uploads/system/uploads/attachment_data/file/215808/ dh_123993.pdf

45 Van Cappellen P, Rice EL, Catalino LI, et al. Positive affective processes underlie positive health behaviour change. Psychol Health 2018;33:77-97.

46 Dittmann KA, Freedman MR, Awareness B. Body awareness, eating attitudes, and spiritual beliefs of women practicing yoga. Eat Disord 2009;17:273-92.

47 Lomas T, Ridge D, Cartwright T, et al. Engagement with meditation as a positive health trajectory: divergent narratives of progress in male meditators. Psychol Health 2014;29:218-36.
48 Ivtzan I, Jegatheeswaran S. The Yoga Boom in Western Society: Practitioners' Spiritual vs. Physical Intentions and Their Impact on Psychological Wellbeing. J Yoga Phys Ther 2015;05.

49 Goyal M, Singh S, Sibinga EMS, et al. Meditation programs for psychological stress and well-being: a systematic review and metaanalysis. JAMA Intern Med 2014;174:357-68.

50 Gaiswinkler L, Unterrainer HF. The relationship between yoga involvement, mindfulness and psychological well-being. Complement Ther Med 2016;26:123-7

51 Diener E, Lucas R, Scollon C. Beyond the hedonic treadmill. American Psychologist 2006;61:305-14.

52 Mochon D, Norton MI, Ariely D. Getting off the hedonic treadmill, one step at a time: the impact of regular religious practice and exercise on well-being. J Econ Psychol 2008;29:632-42

53 Cramer $\mathrm{H}$, Lauche R, Haller $\mathrm{H}$, et al. Effects of yoga on cardiovascular disease risk factors: a systematic review and metaanalysis. Int J Cardiol 2014;173:170-83

54 Cramer H, Ostermann T, Dobos G. Injuries and other adverse events associated with yoga practice: a systematic review of epidemiological studies. J Sci Med Sport 2018;21:147-54.

55 Stommel M, Schoenborn CA. Accuracy and usefulness of BMI measures based on self-reported weight and height: findings from the NHANES \& NHIS 2001-2006. BMC Public Health 2009;9:421.

56 NHS Digital. Health survey for England 2017. Available: https:// digital.nhs.uk/pubs/hse2017, 2017. https://digital.nhs.uk/pubs/ hse2017 